\title{
Nas teias da "rede de proteção": internação compulsória de crianças e adolescentes e a judicialização da vida
}

\author{
Carolina dos Reis, ^ Neuza Maria de Fátima Guareschi \\ Universidade Federal do Rio Grande do Sul, Porto Alegre, RS, Brasil
}

Resumo

\begin{abstract}
Este artigo tem por objetivo problematizar as práticas de internação compulsória de adolescentes por uso de drogas, evidenciando seu uso como uma ferramenta de gestão dessa população que vai ser convocada frente a demanda de recolocar os jovens, considerados desviantes/delinquentes, no lugar da norma. Para desenvolvermos essa discussão analisamos a emergência do uso de drogas como um problema social que convoca os campos de saber a produzir respostas a essa problemática. Como efeito disso, temos a construção de uma categoria populacional de "adolescentes drogaditos" e das formas legitimadas por esses campos do conhecimento de intervir sobre estes. Por fim, trazemos um caso de um personagem, composto a partir de trechos de processos judiciais que nos convida a pensar sobre a forma como a internação compulsória vai se configurar como a principal resposta da rede de serviços, mesmo frente a ausência de resultados da mesma e as consequências possíveis dessa sequência de internações ao longo da vida dos jovens.
\end{abstract}

Palavras-chaves: saúde mental; crianças e adolescentes; uso de drogas; processo de judicialização.

\section{In the webs of "protective network": compulsory hospitalization of children and adolescents and the judicialization of life}

\begin{abstract}
This article aims to discuss the compulsory hospitalization of teenagers for drug use, showing its use as a management tool over this population that is used in face of the demand to reestablish the youth, considered deviant/delinquent, to normality. To develop this debate we analyze the emergence of drug abuse as a social problem that summons the fields of knowledge to produce answers to this problem. As a result, we have the creation of "adolescents drugadiccteds" population category and the forms legitimized by these fields to intervene over them. Finally, we bring a case of a character, composed from lawsuits passages that invites us to think about how the compulsory hospitalization will be configured as the primary response from the public policies, even in the face of the lack of results of it and the possible consequences of this sequence of hospitalizations in the lives of these youths.
\end{abstract}

Keywords: mental health; children and adolescents; drug use; judicialization process.

\section{Introdução}

Este estudo parte de uma preocupação frente ao crescente processo de judicialização do cuidado em saúde mental de jovens usuários de drogas e vem colocar em análise a forma como a internação compulsória tem sido utilizada como ferramenta prioritária e, em muitos casos, exclusiva de tratamento para esses jovens. O agravante é que embora sejam revestidas de discursos de proteção e cuidado as internações vem sendo utilizadas como mecanismo de controle, punição e aumento da vulnerabilidade social dos adolescentes.

Para colocarmos essa problemática em análise, buscamos evidenciar como os adolescentes usuários de drogas vêm a ser afirmados como um novo problema social, associado à criminalidade e à doença, que convoca os campos de saber a produzir respostas a esse problema e o Estado a intervir sobre ele. A partir disso, analisamos o modo como, ao oferecer respostas, os campos de saber operam uma naturalização e individualização de questões econômicas e sociais relacionadas ao uso de drogas. Além disso, buscamos destacar que essa naturalização não fica circunscrita ao indivíduo, mas passa a configurar

\footnotetext{
^Endereço para correspondência: Universidade Federal do Rio Grande do Sul, Programa de Pós-Graduação em Psicologia Social e Institucional. Rua Ramiro Barcelos, 2600, sala 300C - Rio Branco. CEP: 90035003 - Porto Alegre, RS Brasil.E-mail: carolinadosreis@gmail.com,nmguares@gmail.com
}

a construção de uma categoria populacional de "adolescentes drogaditos" potencialmente perigosos e de mecanismos de governo sobre essa população.

Por fim, propomo-nos a analisar como essa inversão das práticas protetivas em punitivas vai se constituir no interior dos Processos Judiciais, por meio da história de um personagem composta a partir das narrativas presentes nos documentos que informam os processos. A história de Francisco convida-nos a pensar sobre o que se faz ver e falar sobre a vida desses jovens no interior dos processos judiciais e contribui para a definição de intervenções que marcam a trajetória desses sujeitos.

\section{A construção da adolescência drogadita como um "novo" problema social}

"Há 10 anos atrás, não tinha nenhum caso no Estado. Estimamos que existam hoje de 50 a 60 mil usuários de crack."

Essa frase, pronunciada pelo então Secretário da Saúde do Estado do Rio Grande do Sul, ${ }^{1}$ é representativa das formas como a relação adolescência e uso de drogas vem sendo apresentada como um problema novo a ser ${ }^{1}$ Essa frase compôs a fala de Osmar Terra, Secretário Estadual da Saúde durante o Governo Yeda Crusius (de 2007 a 2010), em um talk show intitulado Painel RBS “Todos Contra o Crack", promovido pela empresa de multimídia no Barra Shopping Sul, em Porto Alegre, no dia 29 de junho de 2009, como uma das ações de lançamento da campanha "Crack, nem pensar". Essa ação foi divulgada pelos veículos de comunicação do grupo e está disponível em: <http://zh.clicrbs.com. $\mathrm{br} / \mathrm{rs} / \mathrm{mural} / \mathrm{mande}$-sua-pergunta-aos-convidados-do-painel-todos-contra-o-crack-99448.html $\geq$. 
encarado pelos diversos atores sociais. Há 10 anos, praticamente não havia venda de crack no Estado, e a população gaúcha era significativamente menor; no entanto, os ainda mais raros serviços de saúde mental voltados para o atendimento de crianças e adolescentes já se viam superlotados com atendimento de usuários de loló e outros entorpecentes. Logo, a surpreendente novidade aqui não pode estar na existência de um grande número, hoje indiscutivelmente ainda maior, de usuários de drogas no Estado, nem na necessidade de os serviços de saúde se ocuparem do atendimento dessa população. Assim, passamos a estranhar a forma como o uso de drogas por adolescentes emerge, neste momento, como um grande problema para a sociedade, convocando a todos a se envolverem e demandando ações de governo por parte do Estado e respostas dos campos de saber na busca de uma solução.

Em uma pesquisa desenvolvida por Silva et al. (2008) que teve como objetivo evidenciar as transformações naquilo que passa a ser definido como patologia nos modos de ser criança e adolescente, foi realizada uma análise dos prontuários do Hospital Psiquiátrico São Pedro desde sua inauguração, em 1884, até o ano de 1937. A pesquisa realizou, ainda, uma análise comparativa com os dias atuais e constatou que, atualmente, o principal sintoma nos registros de internação é a drogadição e que a pobreza e o encaminhamento judiciário são características predominantes dos processos de internação. Esses dois últimos fatores, a pobreza e a presença de um dispositivo jurídico-policial, mantêm-se constantes ao longo de todos os anos nos casos analisados e ainda se fazem presentes nas internações atuais, evidenciando que a relação entre saberes jurídicos e psiquiátricos em torno da infância e da juventude possui uma longa tradição. A internação aparece como um mecanismo utilizado para dar conta da "ordem pública" e de uma organização e higienização da pobreza: temos um histórico de crianças e adolescentes internados não por apresentarem doença mental, mas por "distúrbios de comportamento".

Não é por acaso, então, que a emergência desse "novo" problema venha associada à proliferação da imagem da adolescência "drogadita" atrelada à violência, afirmadamente provocada pelo descontrole emocional, efeito do uso da substância ou da necessidade de obter dinheiro ou outros bens que possam ser utilizados para adquirir mais entorpecentes. Além disso, essa população de adolescentes, marcada por sua drogadição, passa a ser descrita como em situação de vulnerabilidade social, sendo os adolescentes caracterizados ora como vítimas, ora como protagonistas desse enunciado problema social. Soma-se a isso o fato de que a criminalidade em torno da questão das drogas se tornou um dos temas mais falados da última década, abordando-se desde medidas preventivas até medidas repressivas, bem como seus custos e benefícios ao promoverem a "defesa da sociedade".

Freitas (2009) ressalta que o aumento da violência juvenil e o uso de drogas por adolescentes tendem a remeter, muitas vezes, à busca de uma causa fundamental. O efeito disso é que a fala de especialistas e as produções de determinados campos de saber, ao oferecerem explicações, operam circularmente na própria construção do problema que objetivam elucidar. Essa perspectiva de produção do conhecimento está fundamentada na crença de que haveria uma natureza a ser curada e recuperada nesses adolescentes. $\mathrm{Na}$ busca de uma possibilidade de recuperar o sujeito considerado desviante, a Psicologia, o Direito e os demais campos de saber envolvidos na atenção a crianças e adolescentes, acabam contribuindo para a construção de um modo de ser sujeito usuário de drogas marcado por uma suposta identidade "drogadita/ dependente/viciada/violenta".

Assim, evidenciamos os modos como os adolescentes usuários de drogas vêm sendo investidos enquanto um grande problema social e as estratégias oferecidas para dar conta desse problema. Embora, como afirmamos anteriormente, a violência ou o uso de drogas na adolescência não seja algo novo, é um problema que emerge, neste momento, como novidade. O inovador não está, portanto, na questão em si, mas nas relações que se estabelecem com ela. O que procuramos destacar aqui é que, ainda que os sentidos atribuídos à "adolescência drogadita" sejam datados historicamente, alguns campos do conhecimento que corroboram a construção desses sentidos procuram apagar essa historicidade, atribuindo um caráter essencialista às suas afirmações como descobertas de uma natureza que está na base de um problema social e individual.

\section{A restituição do desviante/doente ao lugar da norma}

Além de atuar na produção dos modos de ser sujeito, o próprio uso da droga teve restritas suas possibilidades de significação pelos campos de saber e já é hoje largamente entendido pela população como uma doença mental que tem seu lugar de tratamento junto aos serviços de saúde. $\mathrm{O}$ efeito dessas produções de campos de saber como a Psicologia pode ser observado nas mudanças efetuadas pelo Direito na legislação. O usuário de droga foi distinguido do traficante, sendo-lhes destinadas diferentes designações legais. O primeiro deve ser encaminhado aos serviços de saúde e submetido à prestação de serviços comunitários, enquanto que, para o segundo, considerado o inimigo a ser combatido, se reserva a prisão. Isso se torna possível pela construção de um conhecimento científico que produz essa diferenciação, na qual o Direito se fundamenta para promover mudanças.

No entanto, ao mesmo tempo em que esses adolescentes são inscritos no lugar de doentes mentais e vítimas do vício, eles não deixam de estar no discurso de atores da criminalidade e da violência perpetrada em função de sua condição patológica. Freitas (2009) descreve um estudo de Travis Hirschi e Michael Gottfredson, intitulado "Uma teoria geral do crime", que afirma que o único fator presente em todas as explicações sobre a violência que poderia se constituir como um explicador final seria o "baixo autocontrole" sobre o comportamento, com uma orientação para o "aqui e agora". Essa justificativa associa-se a produções dos campos de saber sobre adolescentes em situação de vulnerabilidade social, 
que são descritos como imediatistas e sem perspectivas de futuro, tendo em vista o risco de morte que se faz presente no cotidiano. A própria condição adolescente é investida nas produções do campo psi como impulsiva e inconsequente. Somam-se a isso as afirmações sobre o descontrole e a fraqueza frente à potência da droga e de seus efeitos durante o uso e em períodos de abstinência.

A montagem desse quadro contribui para a emergência da noção de que, em estando essa população desprovida de autocontrole, resta como única forma de tratamento possível aquela que se dá pela via da disciplina e da contenção, mesmo que forçada, desse adolescente, afastando-o, ainda que momentaneamente, das ruas, lugar reconhecido como o cenário dessa trama. Deve o Estado, dessa forma, exercer o controle, que se faz deficitário, na vida da população de adolescentes. Encontra-se aí, portanto, a função fundamental do Judiciário, a de intervir em favor da solução oferecida por diversos especialistas como única possível, em nome da garantia do direito à saúde, pelo bem do adolescente, das famílias e da sociedade.

A “adolescência drogadita" torna-se uma questão por estar fora de uma determinada ordem social e atua disseminando a desordem através de algo que vem sendo nomeado pelos especialistas como uma "epidemia das drogas". Constitui-se, portanto, como um problema a ser desvendado e solucionado pela ciência. A produção de algo que está fora da ordem é, então, o que permite a ação, tanto dos campos de saber, quanto do Estado, na busca de uma restituição da população desviante, que ameaça a estabilidade do sistema, ao lugar da norma. A judicialização e a internação psiquiátrica operam como estratégias de normalização desse público delinquente, considerado como tal, se não por atos efetivamente cometidos, por sua condição de semelhança com um sujeito potencialmente criminoso e violento. Os saberes vinculam-se a mecanismos específicos de poder que permitem operar técnicas de normalização exigidas pela população, pelas famílias e, muitas vezes, pelos próprios usuários quando estes se tornam sujeitos dessa cadeia discursiva. Esse poder de normalização, como descrito por Foucault (2001[1974-1975]), não se constitui apenas como o encontro entre os saberes psicológicos e jurídicos, mas atravessa a sociedade moderna. Isto é, embora esse poder de normalização possa apoiar-se nas instituições psi e jurídicas, ele se situa na fronteira entre ambas e está para além destas, com sua autonomia e suas regras próprias.

Ao falarmos em um poder de normalização, referimonos aqui a uma noção de norma que se constituiu através da produção de saberes por áreas das Ciências Humanas sobre os sujeitos, dando-se não mais sobre a doença, mas pela descrição de padrões de conduta objetivos e válidos dentro de uma determinada organização social (CANGUILHEM, 2006[1943]). Como resíduo, surgiram os irredutíveis, não-ajustáveis, sobre os quais se justifica a necessidade de intervenção. Essas estratégias de reinscrição da norma vão focar-se, principalmente, no indivíduo reconhecido como perigoso - não necessariamente o criminoso ou o doente, mas o potencialmente e eventualmente perigoso (FOUCAULT, 2001[19741975). A resposta a essa demanda de intervenção vê-se no desmembramento de tecnologias de governo sobre essa população de adolescentes potencialmente perigosos. Tais tecnologias vão materializar-se tanto nas políticas de justiça e segurança pública quanto nas políticas de saúde, educação e assistência social.

\section{A inscrição da vida dos adolescentes nos mecanismos de gestão do Estado}

A acoplagem da imagem da "adolescência drogadita" à violência é o que favorece a disseminação de sentimentos de insegurança junto à população, consolidando a ideia de uma adolescência potencialmente perigosa ao país. É nessa proliferação do discurso do medo que se vê a emergência da necessidade de busca de novos dispositivos de regulamentação biopolítica sobre os adolescentes (SPOSITO, 2007).

Para Foucault, é essa estratégia que coloca em ação a produção de algo que ele denominou como mecanismos de segurança contra determinados grupos populacionais. Esses mecanismos constituem-se como ações de governo orientadas para a proteção da sociedade frente às condutas desviantes daqueles que ousam insurgir-se contra a sua ordem (FOUCAULT, 2008a[1977-1978]). Não se referem apenas a instituições como a polícia, mas a todas as instituições e funções sociais ramificadas em diferentes pontos da sociedade que servem para assegurar o cumprimento dos regulamentos e o funcionamento dos poderes do Estado (OLIVEIRA, 2009). Abre-se aí um campo frutífero de criação de aparatos de governo sobre a vida de crianças e adolescentes, destinados a gerir suas condutas. Esses sujeitos tornam-se objeto de problematização social, crescendo significativamente o número de políticas públicas destinadas a esse recorte da população.

Ao falarmos em ações de governo sobre a vida desses adolescentes, estamos delineando a produção daquilo que Foucault (2008b[1978-1979]) chamou de biopolítica sobre essa população. A biopolítica é uma tecnologia que compõe o biopoder. Este se refere a um poder do Estado que tem como foco o investimento na vida. Michel Foucault (2008a,[1977-1978]), em seu curso intitulado "Segurança, Território, População", ao definir o que denomina de biopoder, vai evidenciar de que forma, na passagem do século XVIII para o XIX, a vida biológica e a saúde se tornaram alvos fundamentais de um poder sobre a vida através de um processo de estatização do biológico. Com a necessidade de fortalecimento dos Estados-Nação, o poder de vida e morte do soberano foi substituído por um poder destinado a produzir forças, a fazê-las crescer e a ordená-las, mais do que barrá-las, dobrá-las ou destruílas. Fala-se de um poder que gere a vida, que empreende sua gestão, majoração, multiplicação e o exercício de controles precisos e regulações de conjunto.

O biopoder efetiva-se por duas tecnologias: a disciplinar e a biopolítica. A primeira opera sobre os corpos individuais, a partir dos quais procura reger a 
multiplicidade dos homens, colocando em ação técnicas de vigilância, treinamento, ocupação, punição, etc. Já a biopolítica dirige-se à multiplicidade dos homens, não enquanto corpo-indivíduo, mas como corpo-população. A população é entendida, nesse contexto, não como um simples conjunto de pessoas, mas como uma massa global afetada por processos que são próprios da vida, como nascimento, taxas de fecundidade, mortalidade e longevidade. A biopolítica opera sobre a população como um elemento que possui suas regularidades e leis próprias de transformação e deslocamento que são passíveis de serem estudadas e descritas pela ciência. Essa noção de população emerge na segunda metade do século XVIII como um problema político, científico e biológico que pode constituir-se como objeto de saber e alvo de controle (FOUCAULT, 2005[1975-1976]).

Para compreender esse processo, é preciso deixar claro que, quando nos referimos ao Estado dentro da perspectiva descrita por Foucault (2008a[1977-1978]), entendemos que ele não é o centro de irradiação do poder, mas parte de um conjunto de relações de poder. Nesse sentido, referimo-nos a um processo mais amplo que foi colocando a gestão da conduta dos indivíduos e o ato de governar como partes das ações cotidianas dos próprios cidadãos. Esse processo, Foucault denominou de governamentalidade.

Por esta palavra "governamentalidade", entendo o conjunto constituído pelas instituições, os procedimentos, análises e reflexões, os cálculos e as táticas que permitem exercer essa forma bem específica, embora muito complexa, de poder que tem por alvo principal a população, por principal forma de saber a economia política e por instrumento técnico essencial os dispositivos de segurança. Em segundo lugar, por "governamentalidade" entendo a tendência, a linha de força que, em todo o Ocidente, não parou de conduzir, e desde há muito, para a preeminência desse tipo de poder que pode chamar de governo sobre todos os outros - soberania e disciplina - e que trouxe, por um lado, o desenvolvimento de toda uma série de aparelhos específicos de governo [e por outro lado], o desenvolvimento de toda uma série de saberes (FOUCAULT, 2008a[1977-1978], p. 143-144).

A respeito dessa aproximação entre a proliferação de aparelhos de governo e o desenvolvimento dos saberes, Foucault (2010[1979-1980]) descreve, no curso intitulado "Do governo dos vivos", a íntima relação entre o exercício do poder e a manifestação da verdade. Essa articulação sustenta-se na noção de que, para poder governar, seria preciso conhecer o que se governa, quem se governa e o meio de governar esses homens e essas coisas. Nesse sentido é que, ao longo da história, o exercício do poder sempre se fez acompanhar de uma forma de manifestação suplementar da verdade. Em torno do governante, reúne-se todo um ritual de manifestação da verdade, composto de um conjunto de procedimentos verbais e não-verbais, como tabelas, fichas, notas, e as figuras de conselheiros e assessores, o que permite agrupar um núcleo de competências que reafirmem o poder político desse governante.

Fractal, Rev. Psicol., v. 28 - n. 1, p. 94-101, 2016
Estabelece-se aqui a noção do governo pela verdade, o governo como superfície de reflexão da verdade - quanto mais o governo governar pela verdade, menos tomará decisões que se imporão de cima e mais as pessoas aceitarão ser governadas. Tem-se a verdade como produção de uma aceitabilidade. Por outro lado, se todos soubessem de tudo sobre a sociedade, não haveria necessidade de um governo. Logo, está implicada aí a necessidade de constituição de um saber especializado e de uma categoria de indivíduos especializada no conhecimento da verdade (FOUCAULT, 2010[1979-1980]).

Ao apontar-se essa formulação neste estudo, não se trata de empreender esforços na construção de uma sociedade sem relações de poder; trata-se, ao contrário, de colocar o não-poder e a não-aceitabilidade como forma de produzir questionamento sobre os modos segundo os quais se aceita o poder e se aceita ser governado. Resta-nos questionar o que serviu de suporte para tornar aceitável a manutenção de um mecanismo de internação hospitalar como estratégia de punição e higienização de determinados grupos sociais, como a adolescência drogadita. Ainda, interrogar sobre como se torna possível essa inversão na relação protetiva, que se desloca do sujeito para a sociedade, e como essa prática produz desdobramentos nos modos de ser adolescente e distanciamentos entre aqueles sujeitos de direito e esses supostos sujeitos da delinquência.

As formas de intervenção que vão operar sobre a população de adolescentes usuários de drogas não se configuram como uma simples exclusão desses adolescentes, mas como formas de incluí-los e destinarlhes lugares específicos. Trata-se de aproximá-los para melhor entender, categorizar e definir sua presença de forma controlada dentro dos espaços públicos. O reconhecimento como doente mental e a produção desse lugar de destino da internação psiquiátrica operam, por um lado, uma desqualificação jurídica e política dos adolescentes e, por outro, abrem espaço para que as áreas psi reivindiquem o saber sobre esse sujeito e sua doença e o consequente domínio sobre a higiene pública, necessário para a proteção do corpo social. A partir disso, as áreas psi passam a assumir o título de únicas capazes de detectar os perigos inerentes à condição de usuário de drogas.

A disseminação do medo é travestida em alertas, que servem de justificativa e autorização para a execução de intervenções científicas e autoritárias na sociedade sobre essa população. A internação atua como parte de uma estratégia repressiva e proibicionista frente ao uso da droga, sendo pautada pela lógica da abstinência, que coloca a droga como um mal em si e desconsidera todos os aspectos extrafarmacológicos envolvidos no uso, o que inclui questões culturais, políticas e econômicas (OLIVEIRA, 2009). Nesse sentido, Oliveira e Dias (2010, p. 29) alertam que:

As tecnologias políticas avançam a partir daquilo que é essencialmente um problema político, removendo-o do domínio do discurso político e rechaçando-o na linguagem neutra da ciência. Isto feito, os problemas se tornam problemas técnicos para serem debatidos por especialistas. 
Ao destacarmos essa afirmação, queremos pontuar que tanto a internação psiquiátrica quanto a judicialização do cuidado em saúde mental fazem parte de um campo político e nele assumem determinadas funções. Assim, cabe-nos interrogar a serviço do que vêm sendo colocadas essas estratégias de intervenção.

\section{Das histórias de uma vida}

Para podermos pensar sobre essa questão trazemos o relato da história de Francisco. Francisco é um personagem criado a partir da composição de trechos retirados de documentos que compõem processos judiciais de internação compulsória de adolescentes por uso de drogas. Esses documentos foram acessados a partir de uma pesquisa que analisou 14 processos judiciais de sujeitos maiores de 12 anos e menores de 18 , tanto de meninos quanto de meninas, durante os meses de março a julho de 2011, em dois grandes municípios do Rio Grande do Sul. Os processos judiciais foram estudados nos Juizados da Infância e da Juventude de ambos os municípios. Foram selecionados os processos que envolvessem jovens dentro da faixa etária referida, nos quais já houvesse sido determinada a internação compulsória e nos quais não houvesse registro formal de envolvimento com ato infracional. Esse critério relaciona-se com o fato de que buscamos enfocar práticas que operam em nome do cuidado, na tentativa de nos afastarmos daqueles que estão diretamente vinculados às práticas punitivas do sistema socioeducativo. A escolha dos documentos foi feita de forma aleatória a partir dos processos que apresentavam as características descritas e que estavam disponíveis nos Juizados durante o período da pesquisa (março a julho de 2011). O critério que balizou a quantidade de processos analisados foi a saturação dos dados. A consulta aos documentos foi realizada nos próprios Juizados, não tendo sido autorizada a retirada dos documentos do local ou mesmo a reprodução de cópias dos materiais.

A construção de um personagem a partir da composição de algumas das histórias busca evitar a identificação dos casos, preservar a identidade dos adolescentes e familiares e respeitar o segredo de justiça. Da mesma forma, buscamos preservar a identidade dos profissionais, omitindo as especificidades das instituições envolvidas e dos municípios em que os materiais foram coletados. Nessa composição buscamos oferecer ao leitor a possibilidade de acompanhar os passos da história de Francisco em sua trajetória pela "rede de proteção". Não temos aqui a pretensão de analisar as dificuldades e limites presentes na rede de atendimento a esses jovens, pois os materiais analisados não garantiriam esse alcance, mas antes visibilizar a forma como essa rede se apresenta e informa sobre os jovens e suas famílias no interior dos processos a partir dos quais são tomadas decisões que marcam as trajetórias de vida desses adolescentes.

\footnotetext{
Ao usarmos essa expressão entre aspas, não estamos fazendo referência nenhuma rede formalmente constituída, mas sim ao conjunto de atores do campo da saúde, assistência social, educação, justiça, segurança pública e outros que se reúnem em torno da insígnia da proteção, do cuidado e da ressocialização de crianças e adolescentes.
}

Francisco é um personagem, misto de ficção e realidade, tal qual o são os protagonistas das biografias narradas nos documentos que informam os processos judiciais. Mais do que narrarem uma suposta verdade sobre a vida dos jovens, a escolha seletiva acerca das situações narradas e daquelas omitidas, negligenciadas ou desconhecidas pelos profissionais nos documentos que compõem o processo apresenta ao juiz uma versão, dentre muitas possíveis, a respeito daquelas vidas. Desta forma a narrativa sobre Francisco não se constitui somente como uma estilística de escrita, mas busca denunciar o jogo de produção de verdades que forjam a existência dessa categoria populacional.

\section{Sobre o que se fez ver e falar da vida de Francisco}

Francisco começa a tornar-se alvo do olhar atento da "rede de proteção" quando aos 10 anos de idade passa a apresentar comportamentos que desafiam a ordem escolar. De acordo com os documentos emitidos pela instituição escolar ao Ministério Público, o jovem recusa-se a frequentar as aulas. Quando comparece não realiza as atividades propostas e com frequência envolve-se em brigas com os colegas. Os professores descobrem que Francisco permanece na rua no entorno do colégio durante o horário escolar. A mãe do menino em audiência com a Promotoria da Infância e da Juventude conta que o jovem já foi reprovado várias vezes, mas não sabe ao certo quais séries foram repetidas, tampouco em qual esta matriculado. A mãe é viúva e sustenta os sete filhos com uma renda inferior a meio salário mínimo. Descreve o filho como um sujeito preguiçoso e rebelde, sendo estes os motivos identificados por ela como aqueles que o levaram a se afastar dos estudos. Frente a essa situação, a escola buscou "conversar com o jovem para que modificasse seus comportamentos", ${ }^{3}$ o mesmo foi feito com os seus responsáveis, entretanto, estes sequer responderam ao chamado da instituição. A avó informa aos professores com pesar que o jovem "vive solto", "sem o controle de ninguém".

Diante das ausências de Francisco, a escola emitiu uma Ficha de Comunicação de Aluno Infrequente, o FICAI. O FICAI é expedido pela instituição de ensino sempre que um estudante se faz ausente por um período maior que duas semanas. Frente a essa situação a primeira providência é uma tentativa de diálogo com a família. Quando esta ação não produz resultados efetivos, o FICAI é encaminhado à Secretaria de Educação para conhecimento e ao Conselho Tutelar para que este realize busca ativa da família e do jovem e aplique as medidas protetivas ${ }^{4}$ que entender cabíveis. Em seguida o caso é encaminhado ao Centro de Referência de Assistência Social - $\mathrm{CRAS}^{5}$ e/ou ao Centro de Referência Especializado de Assistência Social

\footnotetext{
${ }^{3}$ Os trechos colocados entre aspas são falas presentes no interior dos processos judiciais.

${ }^{4}$ Descritas nos Art. $101^{\circ}$ e $129^{\circ}$ do Estatuto da Criança e do Adolescente - ECA (BRASIL, 1990).

${ }^{5}$ De acordo com o Ministério do Desenvolvimento Social e Combate à Fome, o CRAS é um serviço que compõe o Sistema Único de Assistência Social, junto à Proteção Social Básica. Localiza-se em áreas com maiores índices de vulnerabilidade e risco social e destina-se ao atendimento socioassistencial de famílias.
} 
- CREAS $^{6}$ para elaboração de plano de trabalho junto ao adolescente e sua família, firmando compromissos e disponibilizando recursos para atender às necessidades detectadas e desenvolver potencialidades. Se após essas ações o jovem ainda não houver retornado a escola, o FICAI é encaminhado ao Ministério Público - $\mathrm{MP}^{7}$ "para que o direito à educação deste jovem seja garantido". $\mathrm{O}$ Ministério Público para avaliar o caso chama a família para: audiências, entrevistas com técnicos do judiciário, entrega de documentação comprovatória de renda, matrícula escolar, documentos de identificação, entre outros. No caso de Francisco, após audiência com a Promotoria, na qual "a família foi informada do que poderá acontecer" caso o jovem não retorne à escola, esta se compromete a assegurar a volta do jovem aos estudos. Ao final desta primeira avaliação, o Ministério Público encaminha o caso de Francisco ao Conselho Tutelar - $\mathrm{CT}^{8}$ para que este acompanhe a família e o efetivo retorno do jovem à escola. O Conselho Tutelar, ao receber o ofício do Ministério Público, busca localizar a família no endereço indicado, mas, sem sucesso, devolve o ofício ao MP relatando o ocorrido. O MP encerra o acompanhamento do caso frente a não localização da família.

Um ano depois, a situação se repete e uma nova FICAI do jovem chega ao MP. A família é novamente chamada às audiências, entrevistas com técnicos do judiciário e entrega de novos documentos. Desta vez, a mãe relata que já não sabe mais o que fazer, que o filho não a obedece, que este foge de casa e recusa-se a ir à escola. O MP encaminha o caso novamente ao Conselho Tutelar. O CT busca localizar a família, mas, novamente sem sucesso, informa ao MP e o acompanhamento do caso é mais uma vez arquivado.

Dois anos depois, agora já com quatorze anos, o jovem torna a chamar atenção da "rede" ao ser internado de forma involuntária em um hospital psiquiátrico para tratamento contra drogadição. Os comunicados agora já não chegam ao MP pela escola, mas pelo hospital psiquiátrico. No parecer da equipe, o jovem é descrito como um "sujeito de conduta agressiva, fruto do uso de drogas", ainda, ressaltam que, "quando vai à escola, Francisco busca incitar os demais colegas para o uso de substâncias ilícitas". Neste momento de sua vida, o jovem permanece por alguns períodos na rua e em uma casa supostamente ocupada por traficantes, sustenta-se através das esmolas que recebe. Segundo a avaliação da equipe do hospital, o jovem "responde bem a um ambiente continente e estruturador", "possui funções corticais compatíveis com a idade, concluindo que as deficiências se devem a falta de estímulo e as condições

\footnotetext{
${ }^{6} \mathrm{De}$ acordo com o Ministério do Desenvolvimento Social e Combate à Fome, o CREAS é um serviço que compõe o Sistema Único de Assistência Social, junto à Proteção Social Especial. É responsável pela oferta serviços especializados e continuados a famílias e indivíduos em situação de ameaça ou violação de direitos (violência física, psicológica, sexual, tráfico de pessoas, cumprimento de medidas socioeducativas em meio aberto, etc.).

${ }^{7}$ Segundo a Constituição Federal de 1988, Art. 127º, o Ministério Público é o responsável pela defesa da ordem jurídica, do regime democrático e dos interesses sociais e individuais indisponíveis (BRASIL, 1988).

${ }^{8} \mathrm{O}$ CT é um órgão de proteção, permanente e autônomo, em relação ao Estado, cuja função é zelar pela garantia dos direitos da criança e do adolescente. E composto por cinco membros eleitos através do voto de direto das comunidades onde irão atuar.
}

socioculturais precárias". A indicação é do retorno do jovem para família e seu acompanhamento pela rede de serviços. A internação involuntária é oficiada ao Ministério Público em cumprimento à determinação da lei $\mathrm{n}^{\circ} 10.216$ (BRASIL, 2001) da Reforma Psiquiátrica. ${ }^{9}$

O MP reabre o expediente administrativo relativo ao acompanhamento de Francisco e solicita informações da escola sobre seu retorno. A escola comunica que o jovem está matriculado, mas permanece infrequente e, quando presente, traz tumultos ao ambiente escolar, indica, ainda, que "ouviram que ele esteve internado por drogadição". Na saída desta primeira internação, o jovem, embora passe longos períodos de tempo na rua, retorna eventualmente para a casa da mãe, também retorna para escola, mas segue apresentando comportamentos considerados inadequados pela "rede de proteção". O MP entende que "uma vez que foi internado por drogadição, a evasão escolar deve estar relacionada a isso. Portanto, devese buscar internação compulsória". O Conselho Tutelar é novamente acionado, este relata ao MP que "o jovem é rebelde e vive dizendo que "não dá nada". Frente a isso, aplicam-se as "medidas protetivas" à família e encaminha-se o jovem novamente para internação.

Após essa segunda internação Francisco ainda retorna à escola e à casa da mãe. Desta vez, a escola passa a relatar que o jovem tornou-se extremamente agressivo e que ameaça cotidianamente colegas e professores. De casa, foge frequentemente, retornando acompanhado pelo serviço de abordagem de rua. ${ }^{10}$ Frente a essa situação o MP expede mandado de busca e apreensão do jovem para condução para avaliação médica e posterior internação compulsória para tratamento contra drogadição. O jovem é internado pela terceira vez.

Na saída desta internação, Francisco já não retorna mais para escola, permanece em situação de rua e fazendo uso de drogas, vai esporadicamente para casa da mãe para comer e dormir. Esta "em estado desesperador" busca o Ministério Público para que o jovem seja novamente internado. Franscisco é internado pela quarta vez.

Após a quarta internação Francisco não retorna mais para casa e não aceita a aproximação da mãe. Passa a ser acompanhado pelos técnicos do serviço de abordagem de rua com quem consegue "estabelecer um bom vínculo". Nesse período o jovem já está fixado na situação de rua e mendicância, "faz malabares para conseguir dinheiro e o utiliza para comprar drogas: crack". O serviço de abordagem de rua, preocupado com a situação do jovem, oficia ao MP solicitando que sejam

\footnotetext{
${ }^{9}$ Art. $6^{\circ} \S 1_{-}^{\circ} \mathrm{A}$ internação psiquiátrica involuntária deverá, no prazo de setenta e duas horas, ser comunicada ao Ministério Público Estadual pelo responsável técnico do estabelecimento no qual tenha ocorrido, devendo esse mesmo procedimento ser adotado quando da respectiva alta.

${ }^{10}$ De acordo com o Ministério do Desenvolvimento Social e Combate à Fome, os Serviços Especializados em Abordagem Social são serviços ofertados de forma continuada e programada, com a finalidade de assegurar o trabalho de abordagem e busca ativa que identifique nos territórios a incidência de trabalho infantil, exploração sexual de crianças e adolescentes, situação de rua, dentre outras. Esses serviços ofertam atendimento a crianças, adolescentes, jovens, adultos, idosos e famílias que utilizam espaços públicos como forma de moradia e/ou sobrevivência.
} 
tomadas providências para que Francisco seja novamente internado compulsoriamente para tratamento contra sua drogadição. O jovem é internado pela quinta vez.

Desde a primeira notificação da escola seis anos se passaram. Francisco, agora com 16 anos, já não aceita mais a abordagem dos técnicos, quando estes se aproximam são recebidos a pedradas pelo menino. Frente a isso, o serviço aciona a polícia para que conduza o jovem para uma nova internação. O jovem reage violentamente a intervenção policial, o que acaba por relegitimar sua sexta internação.

Neste percurso do jovem pela "rede de proteção" é possível visibilizar a forma como em torno deste jovem e de sua família vai se organizando isso que Donzelot (1986) denominou de um complexo tutelar. Para o autor esse complexo tutelar terá como um de suas estratégias prioritárias a escola, esta vai ser designada como a instituição padrão, aquela que se constitui como um denominador comum entre todas as crianças e que vai se constituir como um efetivo laboratório de observação de supostas tendências antissociais. Aqui observamos a proliferação de discursos que vão agir em nome da proteção de direitos, mas que inversamente acabam inserindo esse jovem no discurso do risco, potencialmente oferecido por seus comportamentos entendidos como desviantes.

Podemos perceber através desse caso que, mesmo após várias internações psiquiátricas, estas permanecem praticamente como única resposta para a evasão escolar, situação de rua e uso de drogas. A falta de outras respostas do poder público e a sequência de internações acabam por produzir um agravamento na situação do jovem, que vai se afastando da escola e da família e não aceita mais a abordagem dos serviços socioassistenciais. Uma das questões que chamam atenção nesse caso é o fato de que, em dois momentos em que o adolescente havia regressado para casa e voltado a frequentar a escola, ele foi retirado de ambos para ser novamente encaminhado para internação por uso de drogas. A sequência de internações, cada uma com duração média de 21 dias, faz com que jovens como Francisco percam o ano escolar e os afasta cada vez mais da possibilidade de retorno à escola, uma vez que, além de perder aquele ano, fica mais um registro de fracasso pela repetência. A escola acaba operando como mais um meio de exclusão quando não consegue tolerar ou oferecer respostas aos comportamentos considerados desviantes. A Assistência Social e o Conselho Tutelar, por sua vez, funcionam como mecanismos de monitoramento sobre as famílias e os jovens. Para esses serviços, a internação opera como uma ferramenta de punição frente à falta de eficácia de suas outras "medidas protetivas". Quando o jovem afirma que "não dá nada", o Conselho Tutelar busca na "rede de proteção", isto é, na articulação com o Judiciário, com a Assistência Social, Educação e Saúde, o suporte para a legitimação de suas ameaças. A resposta que advém da parceria entre essas instituições para o "não dá nada", afirmado pelo adolescente, é sua internação psiquiátrica, demonstrando-lhe o poder de punição dos órgãos de proteção.
A entrada e saída das unidades de internação acabam constituindo-se como um ciclo contínuo. Para muitos, da mesma forma como ocorre no caso acima, isso tem como efeito o agravamento das condições de vida e a fixação na situação de rua. Quando jovens como este atingem a maioridade, muitos dos acompanhamentos da "rede de proteção" são encerrados sem que tenham conseguido produzir efeitos expressivos no que se refere à mudança nas relações dos jovens com o uso de drogas, tampouco em relação à permanência na rua. O destino final de alguns deles, após a maioridade, quando deixarão de ser objeto de processos judiciais que agem em nome da proteção e do cuidado, é tornarem-se objetos de ações penais, que agem em nome da reinserção social. Alguns, ainda, virão a óbito muito precocemente pelas situações a que ficam expostos. Já outros ficarão sob a proteção do acaso ou desenvolverão estratégias próprias e diversas de sobrevivência, apesar das condições oferecidas por esta sociedade e pelo Estado.

As histórias de jovens como este servem como denúncia da falência das instituições que criamos e da fragilidade dos discursos humanitários e protetivos de que estas últimas são porta-vozes. Em nome da vida e de sua elevação à máxima potência, um conjunto de mecanismos de prevenção expande-se. Entretanto, nunca se matou ou se deixou morrer tanto em nome da vida. As narrativas de vida desses jovens mostram como vai se organizando em torno deles uma série de serviços e saberes que constituem boa parte da maquinaria do Estado. Porém, ao mesmo tempo em que vemos o investimento promovido sobre esses jovens, o efeito final parece direcionar-se, em grande parte, para uma efetiva desproteção e para o agravamento das condições de vida, levando-os ao envolvimento com atos infracionais, à moradia de rua, à evasão escolar, futuramente ao desemprego e até à morte. Em meio às pilhas de documentos produzidas por diversos especialistas, os jovens permanecem abandonados. O que se constitui como objeto de intervenção não são esses sujeitos de carne e osso, mas os "adolescentes drogaditos" e as famílias do risco e da imoralidade, ambos produtos da ciência. São essas categorias populacionais, cientificamente descritas, que refletem muito pouco do dia a dia da vida desses sujeitos que são alvo das intervenções da "rede de proteção".

Ao afirmarmos isso, procuramos destacar que o que impossibilita psicólogos, juízes, promotores, assistentes sociais e pedagogos de perceber que aquele jovem, apesar das condições de vida a que está sujeito, conseguia permanecer na escola e na casa da mãe, é a rigidez das verdades científicas. São verdades que afirmam que o uso de drogas será sempre problemático e para tudo incapacitante. Verdades que fixam identidades como se não tivessem contradições e fossem imutáveis. Verdades que afirmam a essencialização da adolescência e de uma maneira correta de adolescer. Verdades que delimitam territórios de existência, aprisionam e localizam modos de vida em um movimento que busca negar e homogeneizar as multiplicidades e diferenças. 
É em relação a essas verdades que precisamos potencializar rupturas e linhas de fuga. Afirmar outras ciências e outras formas de relação com o conhecimento que possam ser permeáveis à diversidade, que permitam a psicólogos, assistentes sociais, educadores e operadores do Direito perceber a existência de um sujeito para além do desvio e do uso de drogas. A construção dessas ciências parte da responsabilização dos profissionais pelos efeitos de suas práticas e da afirmação destas como ação política. Passamos muito tempo investindo em um poder que tem por objetivo potencializar a vida e, com isso, produzimos múltiplas formas de controle, normatizações e medicalizações. Talvez esteja na hora de apostarmos em práticas de liberdade - não no sentido romântico ou utópico do termo, mas sim na construção de práticas que promovam aberturas e linhas de fuga para outros modos de ser e viver na contemporaneidade.

\section{Referências}

BRASIL. Presidência da República. Casa Civil. Subchefia para Assuntos Jurídicos. Constituição da República Federativa do Brasil de 1988. 1988. Disponível em: <http://www.planalto. gov.br/ccivil_03/Constituicao/ConstituicaoCompilado. htm>. Acesso em: 17 mar. 2012.

BRASIL. Presidência da República. Casa Civil. Subchefia para Assuntos Jurídicos. Lei 8.069 de 13 julho de 1990. Dispõe sobre o Estatuto da Criança e do Adolescente e dá outras providências. 1990. Disponível em: <http://www.planalto. gov.br/ccivil_03/leis/L8069.htm>. Acesso em: 17 mar. 2012.

BRASIL. Presidência da República. Casa Civil. Subchefia para Assuntos Jurídicos. Lei 10.216 de 6 de abril de 2001.

Dispõe sobre a proteção e os direitos das pessoas portadoras de transtornos mentais e redireciona o modelo assistencial em saúde mental. 2001. Disponível em: < http://www.planalto. gov.br/ccivil_03/Leis/LEIS_2001/L10216.htm>. Acesso em: 12 mar. 2011.

CANGUILHEM, G. O normal e o patológico (1943). Rio de Janeiro: Forense Universitária, 2006.

DONZELOT, J. A polícia das famílias. 2. ed. Rio de Janeiro: Graal, 1986.

FOUCAULT, M. Os anormais: curso no Collège de France (1974-1975). Tradução de Eduardo Brandão. São Paulo: Martins Fontes, 2001.

FOUCAULT, M. Em defesa da sociedade: curso no Collège de France (1975-1976). Tradução de Maria Ermantina Galvão. São Paulo: Martins Fontes, 2005.

FOUCAULT, M. Segurança, território, população: curso no Collège de France (1977-1978), tradução de Eduardo Brandão e Claudia Berliner. São Paulo: Martins Fontes, 2008a.

FOUCAULT, M. O nascimento da biopolítica: curso no Collège de France (1978-1979). Tradução de Eduardo Brandão e Claudia Berliner. São Paulo: Martins Fontes, 2008b.

FOUCAULT, M. Do governo dos vivos: curso no Collège de France (1979-1980) excertos. Tradução de Nildo Avelino. São Paulo: Centro Cultural Social; Rio de Janeiro: Achiamé, 2010.
FREITAS, A. S. de. O (des)governo da razão: biopolítica e resistência nas políticas públicas de adolescência. In: CONGRESSO BRASILEIRO DE SOCIOLOGIA, 14., 2009, Rio de Janeiro. Anais... Rio de Janeiro: SBS, 2009. Disponível em: <http://www.sbsociologia.com. $\mathrm{br} / \mathrm{portal} /$ index.php? option $=\mathrm{com}$ _docman\&task $=$ doc download\&gid=3589\&Itemid=171>. Acesso em: 22 jun. 2013.

OLIVEIRA, D. C. Uma genealogia do adolescente usuário de crack: mídia, justiça, saúde, educação. 2009. Dissertação (Mestrado)-Programa de Pós-Graduação em Educação, Universidade Federal de Santa Maria, Santa Maria, 2009.

OLIVEIRA, D. C.; DIAS, M. H. Os adolescentes usuários de crack e a rede de cuidados: problematizações a partir de uma experiência. In: SANTOS, L. B. (Org.). Outras palavras e diferentes olhares sobre o cuidado às pessoas que usam drogas. Porto Alegre: Conselho Regional de Psicologia do Rio Grande do Sul, 2010. p. 27-42.

SILVA, R. N. da et al. (2008). As patologias nos modos de ser criança e adolescente: análise das internações no Hospital Psiquiátrico São Pedro entre 1884 e 1937. PSICO, Porto Alegre, v. 39, n. 4, p. 448-455.

SPOSITO, M. P. (Coord.). Espaços públicos e tempos juvenis: um estudo de ações do poder público em cidades de regiões metropolitanas brasileiras. São Paulo: Global, 2007.

Recebido em: 3 de julho de 2013 Aceito em: 23 de maio de 2015 